\title{
Numerical derivation of averaged material properties of hollow concrete block masonry
}

\author{
Chengqing $\mathrm{Wu}^{1 *}$, Hong $\mathrm{Hao}^{2}$ \\ ${ }^{1}$ School of Civil and Environmental Engineering, the University of Adelaide, North \\ Terrace, SA 5005, Australia \\ ${ }^{2}$ School of Civil and Resource Engineering
}

The University of Western Australia, 35 Stirling Highway, Crawley WA 6009, Australia

\begin{abstract}
Homogenization technique has been used to derive equivalent material properties of masonry units for many years. However, most of the previous research work concentrated on derivation of equivalent material properties for solid brick masonry structure. Very few studies have been conducted to investigate complex mechanical properties of hollow concrete block masonry unit. In this paper, homogenization technique with engineering approach is utilized to derive equivalent material properties from a three-dimensional basic cell of hollow concrete block masonry. In the numerical analysis, a damage model based on the concept of fracture-based damage and stiffness degradation in continuum damage mechanics is applied to modeling the failure of mortar joint and concrete. Two damage variables, one for tensile damage and the other for compressive damage, are introduced to account for the different damage states. The damage model is implemented into a finite element program to derive the equivalent material properties of hollow concrete block masonry. In the basic cell, hollow concrete block and mortar are separately discretized and nonlinear material properties of mortar and concrete are modeled in details. By applying various displacement boundaries on the basic cell surfaces, the equivalent stress-strain relations of hollow concrete block masonry unit are obtained from the numerical analysis. The averaged material properties and failure characteristics of the hollow concrete block masonry unit are then derived from the numerical results. They are then used to model the dynamic response of a hollow
\end{abstract}

* Corresponding author. Tel: 61-8-83034834. Email address: cwu@civeng.adelaide.edu.au 
concrete masonry panel subjected to airblast loading and the same masonry panel is also analyzed with the distinctive material model in which mortar and brick are modeled individually. The efficiency and accuracy of the simple homogenized 3D model are demonstrated.

Key words: Numerical derivation; homogenization; hollow concrete brick; mortar

\section{Introduction}

The equivalent material properties and failure characteristics of hollow concrete brick masonry are different from those of solid brick masonry. For example, current codes of practice usually allow strength enhancement for solid brick masonry under biaxial and triaxial compression. In the case of hollow brick masonry, however, due to lack of knowledge, no strength enhancement is permitted for hollow brick masonry walls in both the Australian (SAA 1998) and Canadian (CSA 1994) codes. In the last decades, much research work has been carried out for the investigation of the complex mechanical properties of solid brick masonry using homogenization technique. One of the earliest homogenization techniques was used to find equivalent elastic properties of in plane solid brick masonry (Pande et al. 1989). Since then, various theoretical and numerical homogenization techniques based on the linear, the non-linear and the limit analysis have been developed to derive equivalent material properties for in-plane and out-of-plane solid brick masonry (Pietruszczak and Niu 1992; Anthoine 1995; Lee et al. 1996; Anthoine 1997; Pegon and Anthoine 1997; DeBuhan and DeFelice 1997; Luciano and Sacco 1997; Luciano and Sacco 1998a,b; Bati et al. 1999; Lopez et al. 1999; Ma et al. 2001; Cecchi A and Di Marco 2002; Cecchi and Sab 2002a,b; Zucchini and Lourenco 2002; Cluni and Gusella 2004; Peerlings et al. 2004; Massart et al. 2004; Cluni and Gusella 2004; Zucchini and Lourenco 2004; Cecchi et al. 2005; Carbone and Codegone 2005; Massart et al. 2005a,b; Calderini and Lagomarsino 2006; Milani et al. 2006a,b,c; Massart et al. 2006; Wu et al. 2006). It has been found that using homogenized masonry material properties yield reliable prediction of masonry performance to both static and dynamic loads, but the computational time is substantially less as compared with the discretized models (Wu et al. 2006). However, most of the previous studies limited on 
solid unit masonry, very few studies have been carried out to investigate homogenized material properties of hollow concrete block masonry. Therefore, it will be of important significance if the equivalent material properties of hollow concrete block masonry can be derived.

Homogenization technique, which permits to establish constitutive relations based on averaged stresses and strains from the geometry and constitutive relations of the individual components, has been employed to derive the equivalent material properties and failure characteristics of solid brick masonry in the last decades (Pietruszczak and Niu 1992; Anthoine 1995; Lee et al. 1996; Anthoine 1997; Pegon and Anthoine 1997; DeBuhan and DeFelice 1997; Luciano and Sacco 1997; Luciano and Sacco 1998a,b; Bati et al. 1999; Lopez et al. 1999; Ma et al. 2001; Cecchi A and Di Marco 2002; Cecchi and Sab 2002a,b; Zucchini and Lourenco 2002; Cluni and Gusella 2004; Peerlings et al. 2004; Massart et al. 2004; Cluni and Gusella 2004; Zucchini and Lourenco 2004; Cecchi et al. 2005; Carbone and Codegone 2005; Massart et al. 2005a,b; Calderini and Lagomarsino 2006; Milani et al. 2006a,b,c; Massart et al. 2006; Wu et al. 2006). In early stage, the homogenization technique for solid brick masonry is to use a simplified geometry to represent the complex geometry of the basic cell so as to obtain a closedform solution of the homogenization problem. Then various complex homogenization techniques have been applied to derive the equivalent material properties and failure mechanism of solid brick masonry. The derived material properties have been successfully used for the analysis of solid brick masonry structures. Homogenization technique has become increasingly popular among the masonry community in recent years. However, many of previous studies handling orthotropic non-linear behavior of solid brick masonry by assuming a yield surface based on only the stress invariants such as Drucker-Prager strength criterion or Mohr-Coulomb strength criterion as usually done for isotropic materials (Ma et al. 2001, Wu et al. 2006). Actually, for hollow concrete masonry, due to its anisotropy its constituent materials do not depend on a DruckerPrager strength criterion or Mohr-Coulomb strength criterion (de Buhan and de Felice 1997; Milani et al. 2006a,b). Therefore a yield function addressing different uniaxial strengths in different directions should be considered for hollow concrete masonry. 
There are only a few studies on the behavior and failure mechanism of hollow concrete block masonry in the past decades (Becica and Harris 1983; Ganesan and Ramamurthy 1992; Sayed-Ahmed and Shrive 1996a; Sayed-Ahmed and Shrive 1996b; Shrive and Sayed-Ahmed 1997; Yi and Shire 2003a; Yi and Shire 2003b). For numerical simulation of hollow concrete block masonry, both shell and continuum FE meshes have been used to perform the analysis. In the simulation, hollow concrete blocks and mortar joints are separately discretized and constitutive laws for each component are adopted. Although these methods can give an accurate prediction of behavior and failure mechanism of hollow concrete block masonry, the main drawback is that they need the large computational effort, therefore are difficult to be applied to realistic masonry structures even with today's computer capability. Homogenization technique, which derives equivalent material properties of composite from suitable relations between averaged strains and averaged stresses of the individual components in the basic cell, can significantly reduce the computational time. To the knowledge of the authors, so far, little information of applying homogenization technique to hollow concrete block masonry to derive its homogenized material properties and failure characteristics can be found in the literature.

In this study, simple homogenization technique and damage mechanics theory are used to model a three-dimensional basic cell to derive the equivalent elastic properties, strength envelope, and failure characteristics of hollow concrete block masonry unit. The basic cell is modeled with distinctive consideration of individual components of mortar and concrete, which are both postulated as isotropic material and have their own material properties such as elastic modulus, strength criterion and damage characteristics. Using the concept of fracture-energy based damage and stiffness degradation in continuum damage mechanics, a plastic damage model is used for both concrete and mortar. In the numerical simulation, various displacement boundaries are applied on the basic cell surfaces to derive the averaged stress-strain relations of the hollow concrete block masonry under different stress states. The averaged elastic properties and failure characteristics of hollow concrete block masonry are then obtained from the simulated 
results. They are utilized to analyze the response of a masonry panel to airblast loading. The same panel is also modeled with distinctive material modeling. The efficiency and accuracy of the simple homogenized model are verified. These averaged material properties can be effectively used to analyze large-scale hollow concrete block masonry structures under blast loads. It should be noted that since the homogenized procedure used in this paper is different from a classic rigorous homogenization approach, it is just an engineering approach based on averaged constitutive quantities.

\section{Homogenization of hollow concrete block masonry with engineering approach}

Hollow concrete block masonry is an orthotropic composite, which is constituted by hollow concrete blocks jointed by mortar joints. Fig. 1 shows the hollow concrete block masonry wall. In the homogenization process with an engineering approach, a basic cell (see Fig. 1), which contains all the geometric and constitutive information of the hollow concrete block masonry, is employed to investigate the complex mechanical properties of the composite material. The hollow concrete block and mortar in the basic cell are modeled, separately, with individual components of mortar and concrete. Using constitutive relations of the individual components of concrete and mortar materials, the constitutive relations of hollow concrete block masonry can be established in terms of the

averaged strains and averaged stresses in the basic cell. The averaged stress and strain $\bar{\sigma}_{i j}$ and $\bar{\varepsilon}_{i j}$ of the basic cell are defined by the integral over the basic cell as

$$
\begin{aligned}
& \bar{\sigma}_{i j}=\frac{1}{V} \int_{V} \sigma_{i j} d V \\
& \bar{\varepsilon}_{i j}=\frac{1}{V} \int_{V} \varepsilon_{i j} d V
\end{aligned}
$$

where $V$ is the volume of the basic cell, $\sigma_{i j}$ and $\varepsilon_{i j}$ are stress and strain in an element. The equivalent material properties of hollow concrete block masonry are then obtained from the simulated stress-strain relations of the basic cell under various loading conditions. 
It should be noted that the assumption of homogeneous distributions of stresses and strains means the volume of the basic cell must be small enough to make the variation of stresses and strains inside it negligible. On the other hand, a basic cell should include all the materials in the masonry to be representative. Based on the above requirements, the basic cell depicted in Fig. 1 is used as a representative volume element although it is relatively large due to large size of the hollow concrete block.

\section{Damage model for concrete and mortar}

Quasi-brittle materials (such as concrete and mortar) under various stresses conditions undergo several damage states, such as tensile cracking, compressive failure and stiffness degradation, it is not realistic to use a single damage variable to represent all damage states. To account for the different damage characteristics in tension and compression, two damage variables $D_{t}$ and $D_{c}$, corresponding to uniaxial tension damage and uniaxial compression damage, respectively, are employed in the present study. Using the fracture release energy to generate microcracks, the uniaxial versions of the two damage variables $D_{c}$ and $D_{t}$ can be defined as (Lubliner et al. 1989)

$$
D_{c}=\frac{1}{G_{f}^{c}} \int_{0}^{\varepsilon_{c}^{p}} \sigma_{c} d \varepsilon_{c}^{p} \quad D_{t}=\frac{1}{G_{f}^{t}} \int_{0}^{\varepsilon_{t}^{p}} \sigma_{t} d \varepsilon_{t}^{p}
$$

where $G_{f}^{c}$ and $G_{f}^{t}$ are the total fracture energy per volume in compression and tension and are defined as

$$
G_{f}^{c}=\int_{0}^{\infty} \sigma_{c} d \varepsilon_{c}^{p} \quad G_{f}^{t}=\int_{0}^{\infty} \sigma_{t} d \varepsilon_{t}^{p}
$$

in which $\sigma_{c}, \sigma_{t}$ are uniaxial compressive and tensile stress, respectively; $\varepsilon_{c}^{p}, \varepsilon_{t}^{p}$ are the scalar plastic strain in compression and tension. Combining the two damage variables, the damage parameter $D$ is then determined by

$$
D=1-\left(1-D_{t}\right)\left(1-D_{c}\right)
$$

This definition indicates the total damage depends on both tensile and compressive damage, but it is not a direct summation of the two damage scalars. 
Analytically convenient functions of the stress-strain diagrams under uniaxial compression and tensions for concrete and mortar can be approximately described with exponential forms as (Lubliner et al. 1989)

$$
\begin{aligned}
& \sigma_{c}=E_{c} \varepsilon_{c} \quad \varepsilon_{c} \leq \varepsilon_{c 0} \\
& \sigma_{c}=\sigma_{c 0}\left[\left(1+a_{c}\right) e^{-\beta_{c}\left(\varepsilon_{c}-\varepsilon_{c 0}\right) / \varepsilon_{c 0}}-a_{c} e^{-2 \beta_{c}\left(\varepsilon_{c}-\varepsilon_{c 0}\right) / \varepsilon_{c 0}}\right] \quad \varepsilon_{c}>\varepsilon_{c 0} \\
& \sigma_{t}=E_{t} \varepsilon_{t} \quad \varepsilon_{t} \leq \varepsilon_{t 0} \\
& \sigma_{t}=\sigma_{t 0}\left[\left(1+a_{t}\right) e^{-\beta_{t}\left(\varepsilon_{t}-\varepsilon_{t 0}\right) / \varepsilon_{t 0}}-a_{t} e^{-2 \beta_{t}\left(\varepsilon_{t}-\varepsilon_{t 0}\right) / \varepsilon_{t 0}}\right] \quad \varepsilon_{t}>\varepsilon_{t 0}
\end{aligned}
$$

where $\sigma_{c 0}, \sigma_{t 0}$ are initial compressive and tensile yield stress defined as the maximum stress without damage and it has $\sigma_{c 0}=E_{c} \varepsilon_{c 0}$ and $\sigma_{t 0}=E_{t} \varepsilon_{t 0}, \varepsilon_{c 0}$ and $\varepsilon_{t 0}$ are the threshold strains that initiate compressive and tensile fracturing of the material; $\beta_{t}$ and $\beta_{c}$ are parameters that control postfailure stress-strain relations of materials in tension and compression, respectively; $a_{c}$ and $a_{t}$ are dimensionless constant, it implies initial hardening when $a_{c}$ or $a_{t}>1$, and softening immediately after yielding while $a_{c}$ or $a_{t}<1$. With the aid of Eqs. (6) to (9), damage parameter in Eq. (5) can be determined. The yield strength for concrete and mortar is modeled by Drucker-Prager strength criterion as

$$
F=\alpha I_{1}+\sqrt{J_{2}}-c(D)=0
$$

where $J_{2}$ is the second invariant of the stress deviator and $I_{1}$ is the first invariant of the stress tensor. Assuming that the post-failure surface satisfies the isotropic softening rule, the constant $\alpha$ remains unchanged, while $c$ will degrade with damage as

$$
c(D)=c_{0}(1-D)
$$

and $\alpha$ and $c_{0}$ are material constants.

From the concept of continuum damage theory, the constitutive relation pertinent to the damage model is described as

where

$$
\{\tilde{\sigma}\}=[\tilde{E}]\{\tilde{\varepsilon}\}
$$

$$
[\tilde{E}]=(1-D)\left[E_{0}\right]
$$


in which $\left[E_{0}\right]$ and $[\tilde{E}]$ are undamaged and damaged elastic constitutive matrix, $D$ is degradation damage parameter that can be determined by Eq. (5).

\section{Numerical results}

The above damage model for concrete and mortar is coded into a finite element program to calculate the stress-strain relations of the basic cell. With the aid of experimental data, it shows that the analytical exponential model in Eq. (6) and (7) or (8) and (9) can define the pre- and postfailure stress-strain relation of material in uniaxial stress state. By fitting the experimental data obtained from previous studies, the parameter values in the analytical exponential forms can be determined. For example, with the aid of experimentally observed uniaxial stress-strain curves for concrete in tension (Gopalarantnam and Shah 1985) and compression (Karsan and Jlrsa 1969), the parameters in the analytical exponential forms are fitted as $a_{c}=3.5, \beta_{c}=0.75, a_{t}=0$ and $\beta_{t}=1.0$, respectively. With these parameter values, a comparison of experimental and analytical stress-train curves for concrete in uniaxial tension and uniaxial compression is illustrated in Fig. 2. As shown, the analytical stress-strain curves agree well with the experimental results obtained by Gopalarantnam and Shah (1985) and Karsan and Jlrsa (1969). For mortar material, parameters in the analytical exponential forms are taken as $\beta_{c}=\beta_{t}=1.0$ and $a_{c}=a_{t}=0$, as they were in a previous study (Ma et al. 2001). The above parameter values for concrete and mortar in the analytical exponential forms are employed in the present study.

Fig. 3 shows a $390 \times 190 \times 190 \mathrm{~mm}^{3}$ hollow concrete block, which is widely used in Australia (http://www.australbrick.com.au). This hollow concrete block and a $10 \mathrm{~mm}$ thick mortar joint are used in this study. In the analysis, the same material properties for bed and head joints are assumed. Table 1 lists the material properties of mortar and concrete used in the numerical simulation. The numerical model of the basic cell of the hollow concrete block masonry is shown in Fig. 4. As shown, the hollow concrete block and mortar in the basic cell are discretized into a number of solid elements. It should be 
noted that convergence tests were conducted to investigate how many elements are needed to achieve a reliable estimation. This is realized by decreasing the size of the element for both brick and mortar by half while keeping loads on the basic cell constant until the difference of the results between two consecutive element sizes is less than $5 \%$. The convergence tests resulted in the selection of the element number that was employed in the simulation. Totally, 1888 eight-node solid elements, in which 1444 elements for hollow concrete block and 444 elements for mortar, are used in the numerical model of the basic cell. Using homogenization technique with engineering approach, a complete monotonic stress-strain relation on the hollow concrete block masonry unit is simulated by applying various boundary conditions.

\subsection{Stress-strain curves}

The representative averaged stress-strain relations of the basic cell under various compressive-compressive boundary conditions are shown in Fig. 5. As shown in Fig. 5 (a), the uniaxial compressive strength of the basic cell in $\mathrm{Z}$ direction without lateral restraint is $14.08 \mathrm{MPa}$, lower than concrete strength (18 MPa), but is almost the same as the compressive strength of mortar (14 MPa). However, without lateral restraint, the uniaxial compressive strengths of the basic cell in X and Y directions are 10.88 MPa and 8.35 MPa respectively, lower than the compressive strength of mortar, implying that the geometry of hollow concrete block influences the compressive strength in $\mathrm{X}$ and $\mathrm{Y}$ direction significantly. The above observations indicate that the geometry of hollow concrete block reduces the compressive strength of the basic cell in both $\mathrm{X}$ and $\mathrm{Y}$ directions. However, the compressive strength in $\mathrm{Z}$ direction is governed by mortar strength. It should be noted that this observation is based on static material properties. Our preliminary study indicated that under high-strain rate dynamic loading, the masonry strength is not necessarily governed by the mortar strength.

Usually, under biaxial and triaxial compressive state, strength enhancement is observed for solid brick masonry in the previous studies (Ma et al. 2001, Wu and Hao 2006). However, this is not the case for hollow concrete block masonry. Fig. 5 (d) shows the 
stress-strain relations of the basic cell under biaxial loading. As shown, without the confinement in Y direction, compressive strengths of hollow concrete block masonry unit in $\mathrm{X}$ and $\mathrm{Z}$ directions are 9.66 $\mathrm{MPa}$ and 13.28 MPa, respectively, slightly smaller than the corresponding uniaxial compressive strengths. The postfailure strains are also smaller than those under uniaxial loading. The results imply that under biaxial loading, the basic cell tends to be more brittle and strength enhancement is not observed. With the lateral restraints in $\mathrm{Y}$ and $\mathrm{Z}$ directions, the maximum compressive strength in $\mathrm{X}$ direction is 11.73 MPa (Fig. 5e), slightly higher than that obtained without lateral restraint. Similarly, if $\mathrm{X}$ and $\mathrm{Y}$ directions are constrained, the compressive strength in $\mathrm{Z}$ direction also increases slightly as shown in Fig. 5 (f). It is noteworthy from Fig. 5(e, f) that in spite of the constraints in $\mathrm{X}$ and $\mathrm{Y}$ or $\mathrm{Y}$ and $\mathrm{Z}$ directions, the averaged strain in $\mathrm{X}$ or $\mathrm{Y}$ directions are not zero, only the averaged strain in $\mathrm{Z}$ direction is zero (see Fig. 5e). This is because the hollow concrete block does not restrain internal deformation in $\mathrm{X}$ and $\mathrm{Y}$ directions. With the confinement in $\mathrm{X}$ direction, the compressive strengths under biaxial loading decrease significantly in $\mathrm{Y}$ and $\mathrm{Z}$ directions as shown in Fig. 5 (g) in comparison with those in Fig. 5 (a-c). It should be noted that due to different dimensions of the basic cell in $\mathrm{Y}$ and $\mathrm{Z}$ directions, the ratio of displacement in $\mathrm{Y}$ and $\mathrm{Z}$ directions shown in Fig. 5 (e) is set to $1: 2(\mathrm{v}: \mathrm{w})$ according to the dimension of the representative element so that the strain ratio in $\mathrm{Y}$ and $\mathrm{Z}$ directions is about $1: 1$. It also should be noted that, the compressive strengths of the basic cell under triaxial loading decrease substantially as shown in Fig. 5 (h), completely different from those obtained from solid brick masonry unit (Wu and Hao 2006). This is also because the hollow brick cannot be restrained internally in $\mathrm{X}$ and $\mathrm{Y}$ directions. These observations indicate that there is no compressive strength enhancement for hollow concrete masonry unit under biaxial and triaxial loading due to the effect of the geometry of hollow concrete block.

For compressive-tensile and tensile-tensile stress states, uniform tensile and compressive displacements are applied to the basic cell surfaces and the corresponding averaged stress and strain of the basic cell are simulated. Fig. 6 shows the simulated stress-strain relations in compressive-tensile and tensile-tensile stress states. As shown from Fig. 6 (a-c), the uniaxial tensile strengths in $\mathrm{X}, \mathrm{Y}$ and $\mathrm{Z}$ directions are 1.16 $\mathrm{MPa}, 0.87 \mathrm{MPa}$ and $1.01 \mathrm{MPa}$, 
respectively. Fig. 6 (d) shows stress-strain curves of hollow concrete block masonry unit under biaxial tensile loading in $\mathrm{X}$ and $\mathrm{Z}$ directions. As shown, the tensile strengths under biaxial tensile loading decrease as compared with those in Fig. 6 (a) and (c). With the lateral confinement in $\mathrm{X}$ direction, tensile strength under biaxial tensile loading in $\mathrm{Z}$ direction reduces slightly, but slightly increases in Y direction, as shown in Fig. 6 (e). It also shows that the averaged strain in $\mathrm{X}$ direction is not zero despite the constraint in $\mathrm{X}$ direction. Under tensile-compressive state, the ultimate tensile strength decreases (see Fig. 6 (f)). It can be observed from Fig. 6 (f) that hollow concrete block masonry unit fails owing to tensile strain before the compressive strength reaches to the maximum value. As expected, the ultimate tensile strength under triaxial tensile loading condition also reduces in the three directions substantially.

Fig. 7 shows the representative stress-strain curves of the basic cell under the compressive-shear and tensile-shear stress-strain state. Under pure shear condition, the ultimate shear strengths $\tau_{z x}, \tau_{z y}$ and $\tau_{y x}$ are 1.01 MPa, 0.51 MPa and 0.16 MPa, respectively (see Fig. 7a-c). The reason why shear stress $\tau_{y x}$ is far less than $\tau_{z x}$ and $\tau_{z y}$ is because there exist two rectangular hollow areas in the concrete block that make the hollow concrete masonry unit very weak under shear stress $\tau_{y x}$. In the in-plane compressive-shear state (Fig. 7d), the shear strength slightly increases. While in the outof-plane compressive-shear state (Fig. 7e), the shear strength decreases. The shear strength also decreases in the tensile-shear state (Fig. 7f). It should be noted that under compressive-shear state, the hollow concrete masonry unit fails due to shear strain before the compressive strength reaches the maximum value.

\subsection{Material properties of the hollow concrete block masonry unit}

Masonry is usually taken as an orthotropic material. The elastic constitutive relation in 3D orthotropic space can be expressed as 


$$
\left[\begin{array}{l}
\varepsilon_{x x} \\
\varepsilon_{y y} \\
\varepsilon_{z z} \\
\varepsilon_{y z} \\
\varepsilon_{z x} \\
\varepsilon_{x y}
\end{array}\right]=\left[\begin{array}{cccccc}
\frac{1}{E_{x x}^{0}} & -\frac{v_{y x}^{0}}{E_{y y}^{0}} & -\frac{v_{z x}^{0}}{E_{z z}^{0}} & 0 & 0 & 0 \\
-\frac{v_{x y}^{0}}{E_{x x}^{0}} & \frac{1}{E_{y y}^{0}} & -\frac{v_{z y}^{0}}{E_{z z}^{0}} & 0 & 0 & 0 \\
-\frac{v_{x z}^{0}}{E_{x x}^{0}} & -\frac{v_{y z}^{0}}{E_{y y}^{0}} & \frac{1}{E_{z z}^{0}} & 0 & 0 & 0 \\
0 & 0 & 0 & \frac{1}{2 G_{y z}^{0}} & 0 & 0 \\
0 & 0 & 0 & 0 & \frac{1}{2 G_{z x}^{0}} & 0 \\
0 & 0 & 0 & 0 & 0 & \frac{1}{2 G_{x y}^{0}}
\end{array}\right]\left[\begin{array}{c}
\sigma_{x x} \\
\sigma_{y y} \\
\sigma_{z z} \\
\tau_{y z} \\
\tau_{z x} \\
\tau_{x y}
\end{array}\right]
$$

Based on the constitutive relation under uniaxial compressive conditions in $\mathrm{X}, \mathrm{Y}$ and $\mathrm{Z}$ directions, the equivalent elastic moduli of the hollow concrete block masonry unit can be derived as

$$
\begin{aligned}
& \bar{E}_{x x}^{0}=\frac{\bar{\sigma}_{x x}}{\bar{\varepsilon}_{x x}}, \bar{v}_{x y}^{0}=\frac{\bar{\varepsilon}_{y y}}{\bar{\varepsilon}_{x x}}, \bar{v}_{x z}^{0}=\frac{\bar{\varepsilon}_{z z}}{\bar{\varepsilon}_{x x}} \\
& \bar{E}_{y y}^{0}=\frac{\bar{\sigma}_{y y}}{\bar{\varepsilon}_{y y}}, \bar{v}_{y x}^{0}=\frac{\bar{\varepsilon}_{x x}}{\bar{\varepsilon}_{y y}}, \bar{v}_{y z}^{0}=\frac{\bar{\varepsilon}_{z z}}{\bar{\varepsilon}_{y y}} \\
& \bar{E}_{z z}^{0}=\frac{\bar{\sigma}_{z z}}{\bar{\varepsilon}_{z z}}, \bar{v}_{z x}^{0}=\frac{\bar{\varepsilon}_{x x}}{\bar{\varepsilon}_{z z}}, \bar{v}_{y z}^{0}=\frac{\bar{\varepsilon}_{y y}}{\bar{\varepsilon}_{z z}}
\end{aligned}
$$

According to the constitutive relation under three pure shear conditions, the shear moduli can be expressed as

$$
\bar{G}_{x y}^{0}=\frac{\bar{\tau}_{x y}}{\bar{\varepsilon}_{x y}}, \bar{G}_{y z}^{0}=\frac{\bar{\tau}_{y z}}{\bar{\varepsilon}_{y z}}, \bar{G}_{z x}^{0}=\frac{\bar{\tau}_{z x}}{\bar{\varepsilon}_{z x}}
$$

Using the simulated data, it was found that the equivalent elastic moduli of the hollow concrete block masonry unit are $E_{x x}^{0}=6.55 \mathrm{GPa}, E_{y y}^{0}=5.43 \mathrm{GPa}, E_{z z}^{0}=7.01 \mathrm{GPa}$, $v_{z x}^{0}=0.258, v_{z y}^{0}=0.262, v_{x y}^{0}=0.282, v_{x z}^{0}=0.253, v_{y x}^{0}=0.279, v_{y z}^{0}=0.248, \bar{G}_{x y}^{0}=2.64 \mathrm{GPa}$, $\bar{G}_{y z}^{0}=2.81$, and $\bar{G}_{z x}^{0}=3.11 \mathrm{GPa}$. It can be observed that the equivalent elastic modulus of the hollow concrete block masonry unit in $\mathrm{Z}$ direction is the largest, while it is the 
smallest in Y direction (out-of-plane). This is mainly because of the geometry effect of hollow concrete block that makes the equivalent elastic modulus in both $\mathrm{X}$ and $\mathrm{Y}$ directions smaller. The Poisson's ratios are also different in the three directions due to geometry influence of hollow concrete block and different distribution patterns of mortar. It should be noted that it is not possible to obtain the out-of-plane homogenized moduli by means of a simple integration of in-plane ones along the thickness (Cecchi and Sab 2002b; Cecchi et al. 2005).

\subsection{Yield criterion}

The strength characteristics of masonry are very important in modelling masonry damage. Using the ultimate strength from the stress-strain curves shown in Figs. 5 to 7, the equivalent strength envelope for hollow concrete block masonry unit can be derived. As hollow concrete masonry is an orthotropic material, its uniaxial compressive strengths in different directions are quite different. Fig. 8(a) shows the simulated two-invariant points in $I_{1} \sim \sqrt{J_{2}}$ space. As shown, due to the scatter of the two-invariant data, its strength envelope cannot be reliably expressed as a piecewise linear model or a cap model in $I_{1} \sim \sqrt{J_{2}}$ space as for the solid brick masonry (Ma et al., 2001; Wu and Hao 2006). Therefore, conventional strength criteria in terms of the stress invariant $I_{1}$ and $J_{2}$, such as the Drucker-Prager or Mohr-Coulomb strength criterion, are not suitable for representing the strength envelope of the orthotropic hollow concrete block masonry. In order to describe the complex mechanical behavior of orthotropic material, a new yield function, which takes into consideration the difference in uniaxial strengths in different directions, is suggested in this study. It is given in terms of an equivalent first stress invariant $\mathrm{X}$ and an equivalent second stress invariant $\sqrt{\mathrm{Y}}$ as

$$
\begin{gathered}
\mathrm{X}=A \sigma_{x x}+B \sigma_{y y}+C \sigma_{z z} \\
\sqrt{\mathrm{Y}}=\sqrt{D \sigma_{x x}^{2}+E \sigma_{y y}^{2}+F \sigma_{z z}^{2}+G \tau_{x y} \tau_{y z}+H \tau_{y z} \tau_{z x}+I \tau_{z x} \tau_{x y}}
\end{gathered}
$$

where $A, B, C, D, E, F, G, H$ and $I$ are material constants. Using the simulated data, it is found that $A=0.48, B=0.63, C=0.39, D=0.23, E=0.38, F=0.15, G=-$ 
$0.34, H=-0.3$, and $I=-0.3$. Fig. 8 (b) shows the simulated equivalent strength envelope in $\mathrm{X} \sim \sqrt{\mathrm{Y}}$ space. As shown, the yield function can be expressed as

$$
\bar{F}_{i}=\alpha_{i} \mathrm{X}+\sqrt{\mathrm{Y}}+k_{i}=0 \quad i=1,2,3
$$

where $\alpha_{i}, k_{i}$ are parameters that control piecewise linear parts of the strength model in $\mathrm{X} \sim \sqrt{\mathrm{Y}}$ space. Using the equivalent stress invariants in $\mathrm{X} \sim \sqrt{\mathrm{Y}}$ space, $\alpha_{i}, k_{i}$ are found to be -0.36 and $0.44 \mathrm{MPa}$ for $\bar{F}_{1},-0.92$ and $0.44 \mathrm{MPa}$ for $\bar{F}_{2}$, and 0.67 and 8.85 MPa for $\bar{F}_{3}$.

With the simulated stress-strain relations of the basic cell, the threshold tensile strains corresponding to the maximum tensile stresses in $\mathrm{X}, \mathrm{Y}$, and $\mathrm{Z}$ direction are $1.45 \times 10^{-4}$, $1.54 \times 10^{-4}$, and $1.73 \times 10^{-4}$, respectively. The equivalent threshold tensile strain can be calculated by formulae $\sqrt{\left(\bar{\varepsilon}_{x x}^{+2}+\bar{\varepsilon}_{y y}^{+2}+\bar{\varepsilon}_{z z}^{+2}\right) / 3}$, that is, $1.58 \times 10^{-4}$ in the present study. The threshold tensile strains will be used in the masonry damage model.

\subsection{Size influence and simple homogenized model for hollow concrete block masonry}

As discussed in Section 2, the basic cell in the simple homogenization process should be as small as possible because the stress and strain distributions are assumed uniform inside it. On the other hand, the basic cell should be large enough so that the materials of different constituents can be included. Although the basic cell in the present study satisfies the basic requirements (Anthoine 1995), size influence of the basic cell should be examined in order to assure the reliability of the averaged properties of the hollow concrete block masonry. A panel formed by $2 \times 2$ basic cells is used to examine the size effect of the basic cell. Two special displacement conditions, i.e., uniform compressive displacement and uniform tensile displacement are applied on the horizontal surfaces of the unit, representing the stress-strain states of the unit in uniaxial compression and uniaxial tension. Fig. 9(a) shows the comparison of the uniaxial compressive stress-strain curves under two different units. It demonstrates that the elastic part of the two curves coincide very well, but the initial failure stress of the $2 \times 2$ basic cell decreases by about 
40 percent in comparison with that of the basic cell. Therefore, the elastic properties of hollow concrete block masonry are almost independent of the size of the basic cell in the simple homogenization process in the uniaxial compressive state. Similar situations occur for the stress-strain curves in unixail tensile state as shown in Fig. 9(b). The above results imply that the geometry of hollow concrete block has significant influence on the averaged stress and strain values of the basic cell; averaged masonry material properties from a basic cell larger than the one used in this study may contain significant size or structure effect. Nonetheless, the basic cell used in this study is the smallest possible unit that contains both brick and mortar materials. The validity of the averaged material properties in modeling masonry response to blast load will be demonstrated in the next section.

With the aid of the averaged material properties, the constitutive relation for the homogenized hollow concrete block masonry at macro level can be expressed as

$$
\left[\bar{E}^{e p}\right]=[\bar{E}]-\frac{[\bar{E}] \frac{\partial \bar{G}}{\partial\{\sigma\}} \frac{\partial \bar{F}}{\partial\{\sigma\}^{T}}\{\bar{E}\}^{T}}{\bar{H}+\frac{\partial \bar{F}}{\partial\{\sigma\}^{T}}[\bar{E}] \frac{\partial \bar{G}}{\partial\{\sigma\}}}
$$

where $\left[\bar{E}^{e p}\right]$ is the elastoplastic incremental material matrix; $\bar{F}$ is the yield function derived above; $\bar{G}$ is a plastic potential function which is identical to the yield function if an associated flow rule is assumed; $\bar{H}$ is a stiffness hardening parameter

$$
\bar{H}=-\frac{\partial \bar{F}}{\partial \varepsilon_{i j}^{p}} \frac{\partial G}{\partial \sigma_{i j}}-\frac{\partial F}{\partial k} \frac{\partial k}{\partial \varepsilon_{i j}^{p}} \frac{\partial G}{\partial \sigma_{i j}}
$$

and $[\bar{E}]$ is the damaged elastic matrix, which can be expressed as

$$
[\bar{E}]=(1-\bar{D})\left[\bar{E}^{0}\right]
$$

where $\left[\bar{E}^{0}\right]$ is initial averaged orthotropic elastic modulus matrix in three directions, $\bar{D}$ is damage scalar which is defined as

$$
\bar{D}=1-\exp \left(-\bar{\beta}\left(\bar{\varepsilon}^{+}-\bar{\varepsilon}_{0}^{+}\right) / \bar{\varepsilon}_{0}^{+}\right)
$$


where $\bar{\varepsilon}^{+}$is the equivalent tensile strain of masonry and can be determined by $\bar{\varepsilon}^{+}=\sqrt{\sum_{i=1,3}\left(\varepsilon_{i}^{+}\right)^{2}} ; \bar{\beta}$ is a damage parameter, it is set to 0.5 based on the previous study (Ma et al. 2001); and $\bar{\varepsilon}_{0}^{+}$is the threshold tensile strain which is equal to $1.58 \times 10^{-4}$ in the present study.

\subsection{Applications}

The developed simple homogenized material model is used to simulate response of a $1.8 \mathrm{~m} \times 2 \mathrm{~m}$ hollow concrete masonry panel under airblast loads. The same masonry panel is also analyzed with distinctive model with clearly modeling of brick and mortar for a comparison. Fig. 10 shows numerical models of the two masonry panels. The two panels have fixed boundary conditions. The pressure time histories estimated from a previous study as shown in Fig. 11 are applied on the surface of the masonry panels as input to perform the analysis (Wu and Hao 2005). They represent reflected airblast pressures on structures from an explosion of $1000 \mathrm{~kg}$ at a distance $40 \mathrm{~m}$ and $30 \mathrm{~m}$ respectively. Fig. 12 shows deformation of the hollow concrete masonry panels to airblast load at a distance $40 \mathrm{~m}$ at $0.2 \mathrm{~s}$ with distinctive model and simple homogenized model. As shown, both the simple homogenized model and distinctive model gives similar prediction of the masonry panel response to the airblast load. However, the time spent for the distinctive model to solve the problem in an Intel Pentium $43500+2.21 \mathrm{GHz}$ with $2 \mathrm{MB}$ memory is $1494 \mathrm{~s}$ while only $58 \mathrm{~s}$ is taken for the simple homogenized model. Fig. 13 illustrates deformation of the masonry panels to airblast load at a distance $30 \mathrm{~m}$ at $0.05 \mathrm{~s}$ with distinctive model and simple homogenized model. Again, similar responses are observed from the both models.

It should be noted that although the simple homogenized model give reliable prediction of masonry damage to blast loads, it may not yield accurate prediction of masonry fragmentation, i.e., fragment size and ejection velocity. This is because the weak mortar joints may significantly influence the fragmentation. However, our preliminary study 
indicated that mortar joint strength governs the masonry strength only when strain rate is low. At high strain rate, mortar strength does not necessarily dominate the masonry strength, and brick units may also suffer sudden brittle failure under blast loading. More study is deemed necessary to investigate the reliability of using averaged masonry material properties in simulating masonry fragmentation to blast loads.

\section{Conclusions}

Homogenization technique with engineering approach has been employed to derive the equivalent material properties of hollow concrete block masonry unit. The elastic moduli, strength envelope and failure characteristics have been derived by numerical simulation of the basic cell under various boundary conditions. The simulated Young's modulus and ultimate uniaxial compressive strength in vertical direction $(z)$ are the largest due to the influence of the geometry of hollow concrete block. Unlike solid brick masonry, the strengths of the hollow concrete masonry unit under biaxial loading and triaxial loading are not enhanced. Owing to the significant differences among uniaxial compressive strengths in different directions, yield criteria such as Drucker-Prager or Mohr-Coulomb strength criterion in terms of stress invariants, are not suitable for hollow concrete block masonry. An equivalent first stress invariant $\mathrm{X}$ and a second stress invariant $\sqrt{\mathrm{Y}}$ are proposed to model the hollow masonry strength in $\mathrm{X} \sim \sqrt{\mathrm{Y}}$ space. It has been demonstrated that the size effect is not pronounced to the equivalent elastic modulus, but significant to the yield strength of the masonry material. A smallest possible basic cell should be used in deriving the averaged masonry material properties. It has also been demonstrated that using the homogenized masonry material properties yield reliable prediction of masonry wall damage to blast loads, but the computational time is substantially less as compared with the distinctive modeling. 


\section{Acknowledgements}

The authors would like to acknowledge the financial support from the Australian Research Council (ARC) under grant number DP0451966 for carrying out this research work.

\section{References}

- Anthoine A. Derivation of the in-plane elastic characteristics of masonry through homogenization theory. International Journal of Solids and Structures, 32 (2), 137-163, 1995.

- Anthoine A. Homogenization of periodic masonry: Plane stress, generalized plane strain or 3D modelling? Communications in Numerical Methods in Engineering, (5), 319-326, 1997.

- Bati SB, Ranocchiai G, Rovero L. A micromechanical model for linear homogenization of brick masonry. Materials and Structures, 32 (215), 22-30, 1999.

- Becica IJ, Harris HG. Behavior of hollow concrete masonry prisms under axial load and bending. The Masonry Society Journal, 2(2), 1-26, 1983.

- Berto L, Saetta A, Scotta R, Vitaliani et al. An orthotropic damage model for masonry structures. International Journal for Numerical Methods in Engineering 55 (2), 127-157, 2002.

- Calderini C, Lagomarsino S. A micromechanical inelastic model for historical masonry. Journal of Earthquake Engineering, 10 (4), 453-479, 2006.

- Carbone VI, Codegone M. Homogenization process of stratified masonry. Mathematical and Computer Modelling 42 (3-4), 375-380, 2005

- Cecchi A, Di Marco R. Homogenized strategy toward constitutive identification of masonry. Journal of Engineering Mechanics, ASCE, 128 (6), 688-697, 2002.

- Cecchi A, Milani G, Tralli A. Validation of analytical multiparameter homogenization models for out-of-plane loaded masonry walls by means of the 
finite element method. Journal of Engineering Mechanics, ASCE, 131 (2), 185198, 2005.

- Cecchi A, Sab K. A multi-parameter homogenization study for modeling elastic masonry. European Journal of Mechanics A-Solid, 21 (2), 249-268 2002a.

- Cecchi A, Sab K. Out of plane model for heterogeneous periodic materials: the case of masonry. European Journal of Mechanics A-Solid, 21 (5), 715-746 2002b.

- Cluni F, Gusella V. Homogenization of non-periodic masonry structures. International Journal of Solids and Structures, 41 (7), 1911-1923, 2004.

- CSA. Masonry design for buildings (limit states design) structures (design). Standard CSA-S304.1-94, Canadian Standards Association, Rexdale, Ont, 1994.

- DeBuhan P, DeFelice G. A homogenization approach to the ultimate strength of brick masonry. Journal of the Mechanics and Physics of Solids 45 (7), 1085-1104, 1997.

- Ganesan TP., Ramamurthy K. Behavior of concrete hollow block masonry prisms under axial compression. Journal of Structural Engineering, ASCE, 118(7), 17511769, 1992.

- Lee JS, Pande GN, Middleton J, Kralj B. Numerical modeling of brick masonry panels subject to lateral loadings. Computers \& Structure 61 (4): 735-745, 1996.

- Lopez J, Oller S, Onate E, Lubliner J. A homogeneous constitutive model for masonry. International Journal for Numerical Methods in Engineering 46 (10), 1651-1661, 1999.

- Lubliner J., Oliver J., Oller S., Onate E. A plastic-damage model for concrete. International Journal of Solids and Structures, 25 (3), 299-326, 1989.

- Luciano R and Sacco E. Homogenization technique and damage model for masonry material. International Journal of Solids and Structures, 34 (24), 31913208, 1997.

- Luciano R, Sacco E. A damage model for masonry structures. European Journal of Mechanics A-Solid, 17 (2), 285-303, 1998b.

- Luciano R, Sacco E. Variational methods for the homogenization of periodic heterogeneous media. European Journal of Mechanics A-Solid, 17 (4), 599-617, 1998a. 
- Ma GW, Hao H, Lu Y. Homogenization of masonry using numerical simulation. Journal of Engineering Mechanics, ASCE, Vol. 127 (5), 421-431, 2001.

- Massart TJ, Peerlings RHJ, Geers MGD, Gottcheiner S. Mesoscopic modeling of failure in brick masonry accounting for three-dimensional effects. Engineering Fracture Mechanics, 72 (8), 1238-1253, 2005.

- Massart TJ, Peerlings RHJ, Geers MGD. Mesoscopic modeling of failure and damage-induced anisotropy in brick masonry. European Journal of Mechanics ASolid, 23 (5), 719-735, 2004.

- Massart TJ, Peerlings RHJ, Geers MGD. An enhanced multi-scale approach for masonry wall computations with localization of damage. International Journal for Numerical Methods in Engineering (in press 2006).

- Milani G, Lourenco PB, Tralli A. Homogenised limit analysis of masonry walls, Part I: Failure surfaces. Composites \& Structures, 84 (3-4), 166-180, 2006b.

- Milani G, Lourenco PB, Tralli A. Homogenised limit analysis of masonry walls, Part II: Structural Examples. Composites \& Structures, 84 (3-4), 181-195, 2006c.

- Milani G, Lourenco PB, Tralli A. Homogenization approach for the limit analysis of out-of-plane loaded masonry walls. Journal of Structural Engineering, ASCE, 130(10), 1650-1663, 2006a.

- Pande GN, Liang JX, Middleton J. Equivalent elastic moduli for brick masonry. Computers \& Geotechnics, 8, 243-265, 1989.

- Peerlings RHJ, Massart TJ, Geers MGD. A thermodynamically motivated implicit gradient damage framework and its application to brick masonry cracking. Computer Methods in Applied Mechanics and Engineering, 193 (30-32), 34033417, 2004.

- Pegon P, Anthoine A. Numerical strategies for solving continuum damage problems with softening: Application to the homogenization of masonry. Computers \& Structures, 64 (1-4), 623-642, 1997.

- Pietruszczak S, Niu XA. A mathematical description of macroscoptic behavior of unit masonry. International Journal of Solids and Structures, 29 (5), 531-546, 1992. 
- SAA. Masonry in buildings. Standard SAA-AS 3700, Standard Association of Australia, Sydney, N.S.W., 1998.

- Sayed-Ahmed EY, Shrive NG. Design of face-shell bedded hollow masonry subject to concentrated loads. Canadian Journal of Civil Engineering Vol. 23 (1), 98-106, 1996a.

- Sayed-Ahmed EY, Shrive NG. Nonlinear finite-element model of hollow masonry. Journal of Structural Engineering, ASCE, 122(6), 683-690, 1996b.

- Shrive NG, Sayed-Ahmed EY. Design recommendations for hollow concrete masonry walls subject to concentrated loads, based on a test program. Canadian Journal of Civil Engineering Vol. 24 (3), 380-391, 2003a.

- Wu C, Hao H. Modeling of simultaneous ground shock and airblast pressure on nearby structures from surface explosions. International Journal of Impact Engineering, 2005; 31(6): 699-717.

- Wu C., Hao, H. Derivation of 3D masonry properties using numerical homogenization technique. International Journal for Numerical Methods in Engineering 66, 1717-1737, 2006.

- Yi J., Shrive NG. Behavior of hollow concrete masonry walls with one-course bond beams subjected to concentric and eccentric concentrated loading. Canadian Journal of Civil Engineering Vol. 30 (1), 159-168, 2003a.

- Yi J., Shrive NG. Design rules for hollow concrete masonry walls subjected to concentrated loads. Canadian Journal of Civil Engineering Vol. 30 (1), 203-213, 2003b.

- Zucchini A, Lourenco PB. A micro-mechanical model for the homogenisation of masonry. International Journal of Solids and Structures, 39 (12), 3233-3255, 2002.

- Zucchini A, Lourenco PB. A coupled homogenisation-damage model for masonry cracking. Computers \& Structures, 82 (11-12), 917-929, 2004. 
Table 1 Material properties for concrete and mortar

(a) concrete

\begin{tabular}{|c|c|c|c|c|c|c|}
\hline$E(\mathrm{GPa})$ & $G_{c}(\mathrm{GPa})$ & $v$ & $\sigma_{t}(\mathrm{MPa})$ & $\sigma_{c}(\mathrm{MPa})$ & $\varepsilon_{\text {to }}$ & $\varepsilon_{c o}$ \\
\hline 14.0 & 5.6 & 0.25 & 1.6 & 18.0 & 0.00011 & 0.0013 \\
\hline
\end{tabular}

(b) Mortar

\begin{tabular}{|c|c|c|c|c|c|c|}
\hline$E(\mathrm{GPa})$ & $G_{c}(\mathrm{GPa})$ & $v$ & $\sigma_{t}(\mathrm{MPa})$ & $\sigma_{c}(\mathrm{MPa})$ & $\varepsilon_{\text {to }}$ & $\varepsilon_{c o}$ \\
\hline 5.8 & 2.2 & 0.33 & 1.0 & 14.0 & 0.00045 & 0.0024 \\
\hline
\end{tabular}



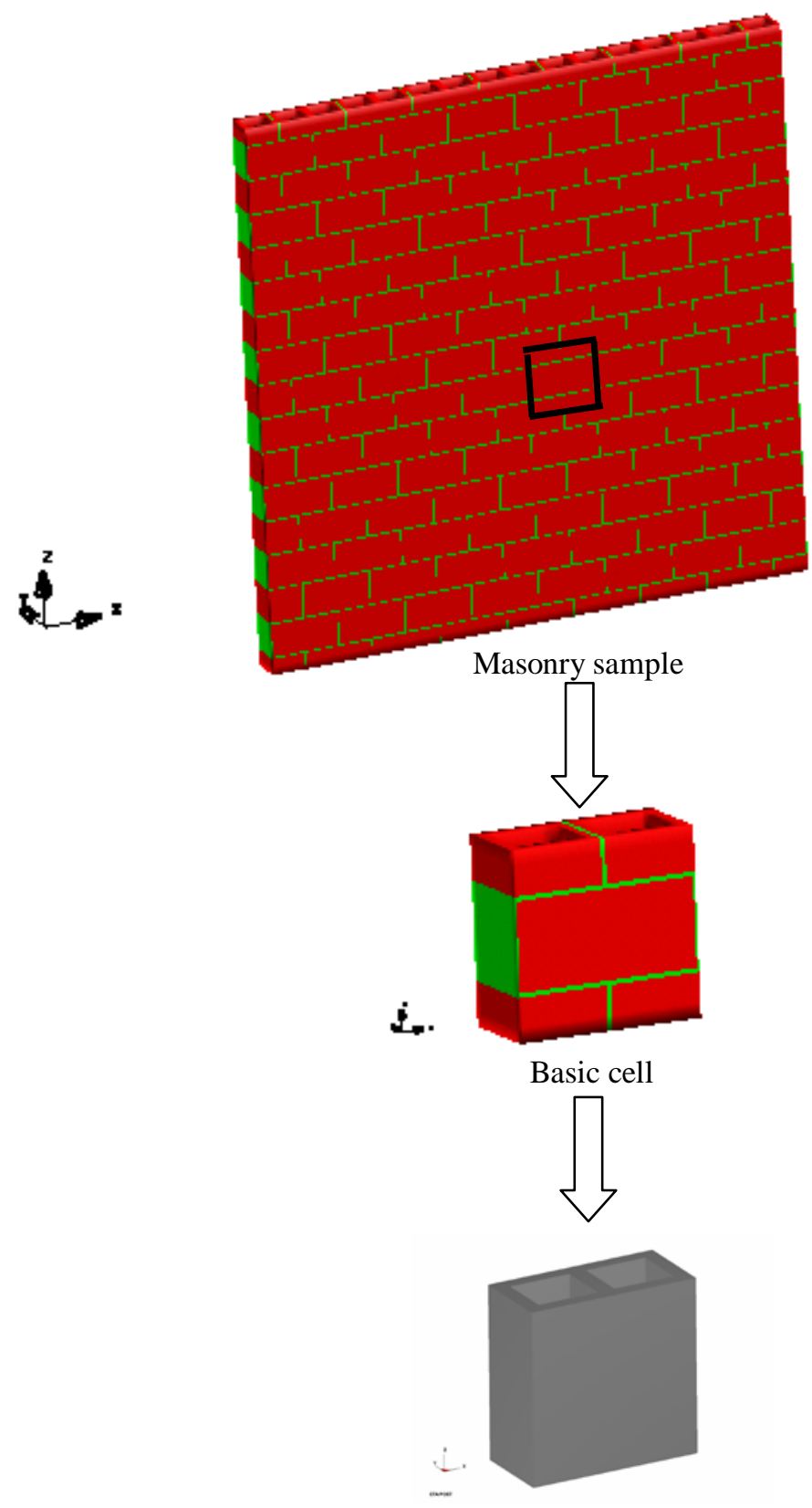

Homogenization

Fig. 1 Homogenization of hollow concrete block masonry 


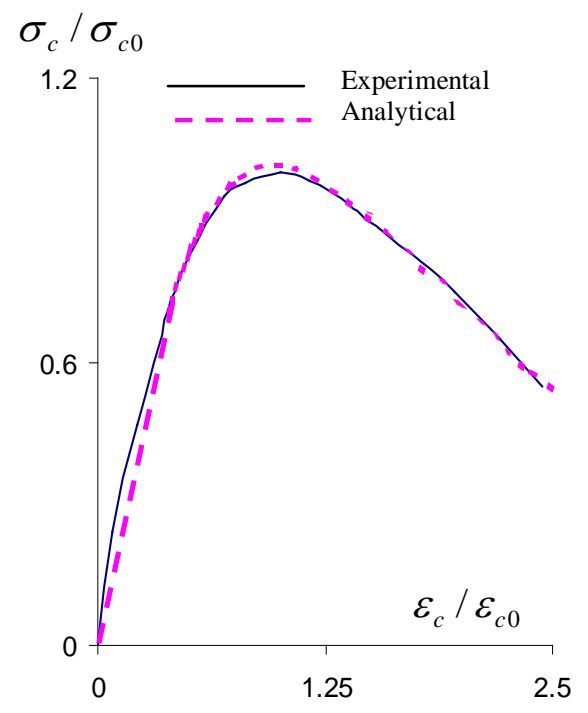

a. Uniaxial compressive stress-strain relations

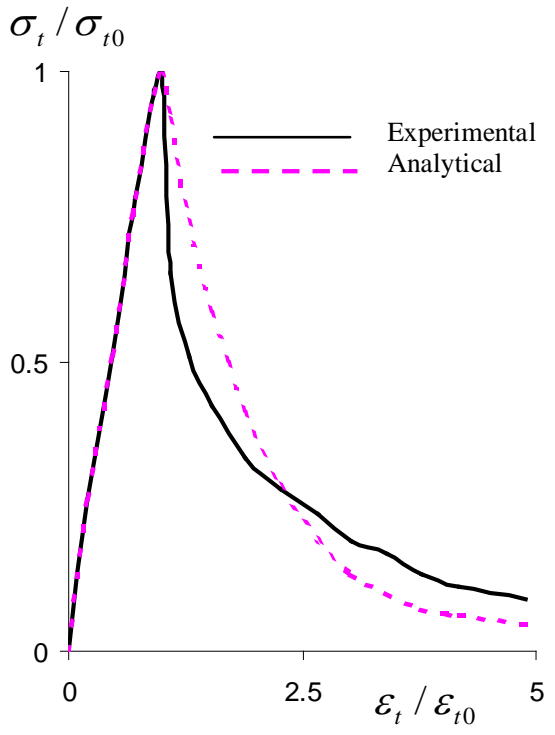

b. Uniaxial tensile stress-strain relations

Fig. 2 Comparison of experimental and analytical stress-train curves of concrete in uniaxial compression and uniaxial tension 


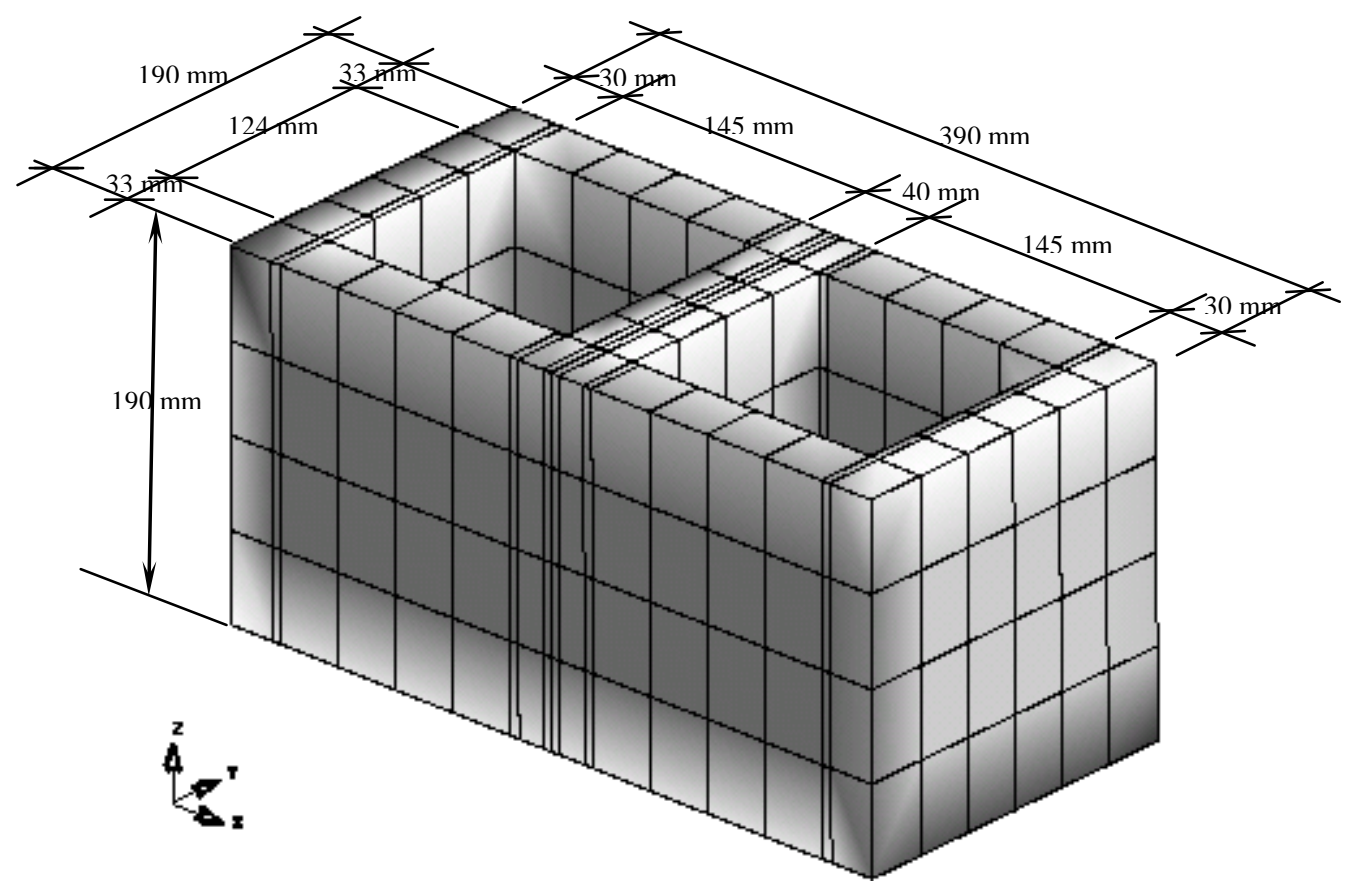

Fig. 3 Detail dimensions of the hollow concrete block 


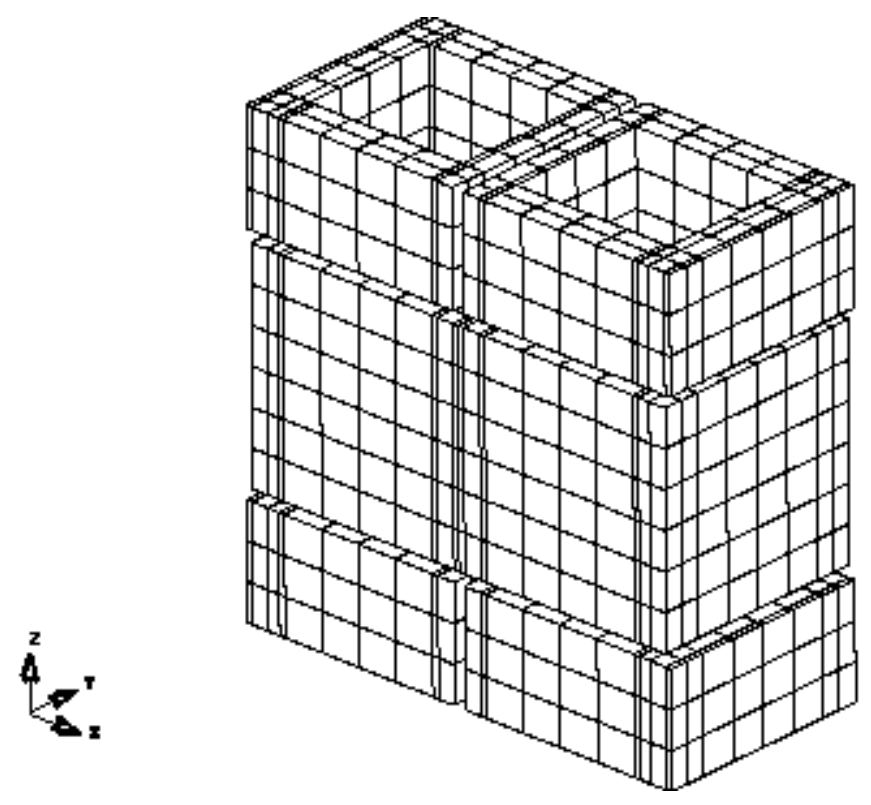

(a) concrete block

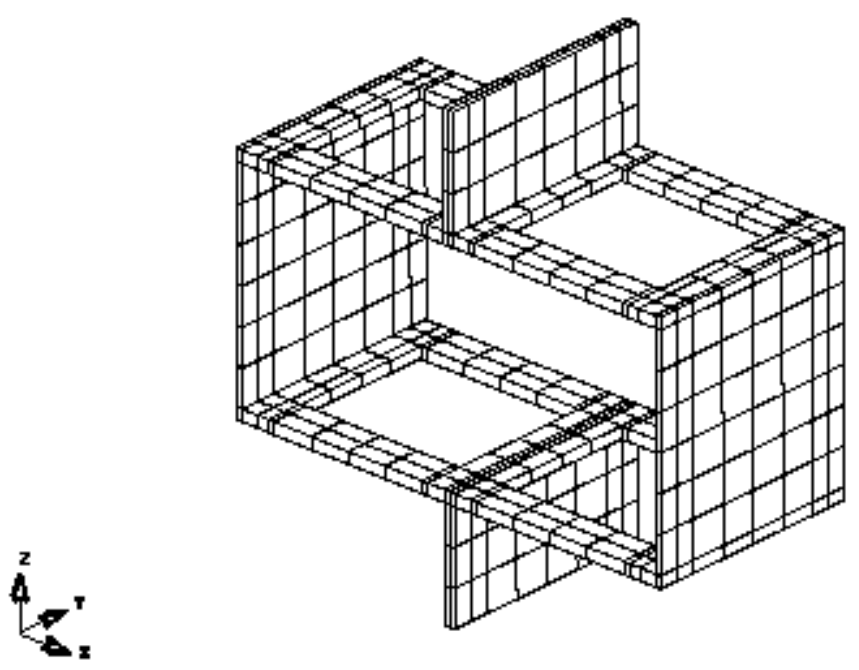

(b) mortar

Fig. 4 Numerical model of the basic cell of hollow concrete block masonry 


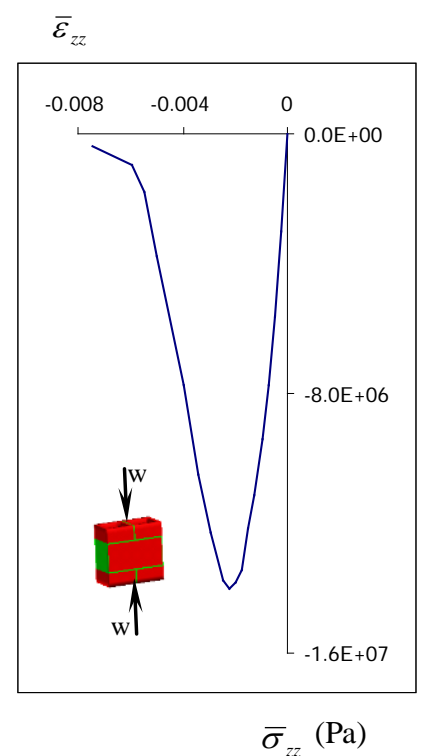

(a)

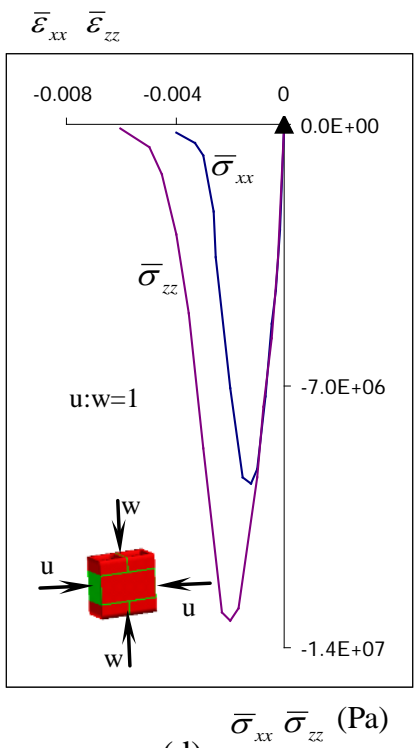

(d)

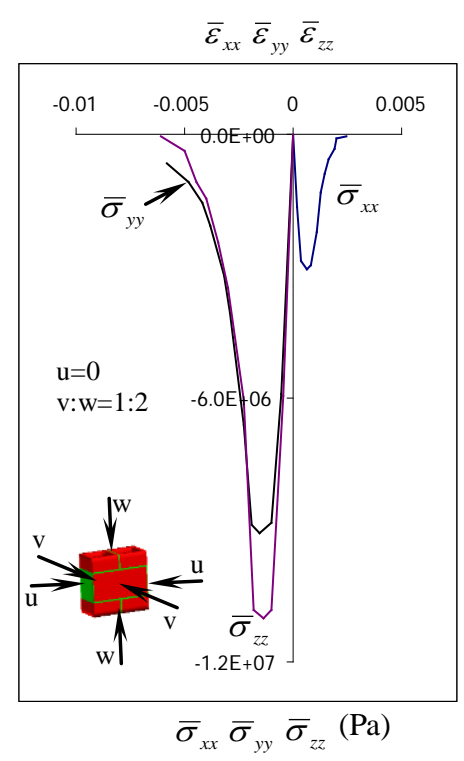

(g)

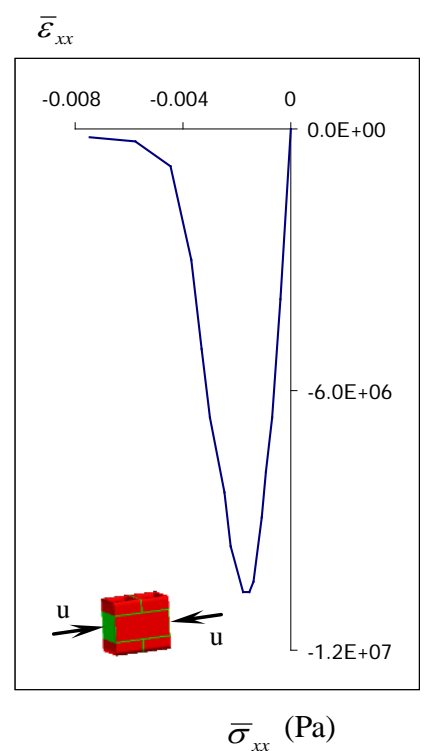

(b)

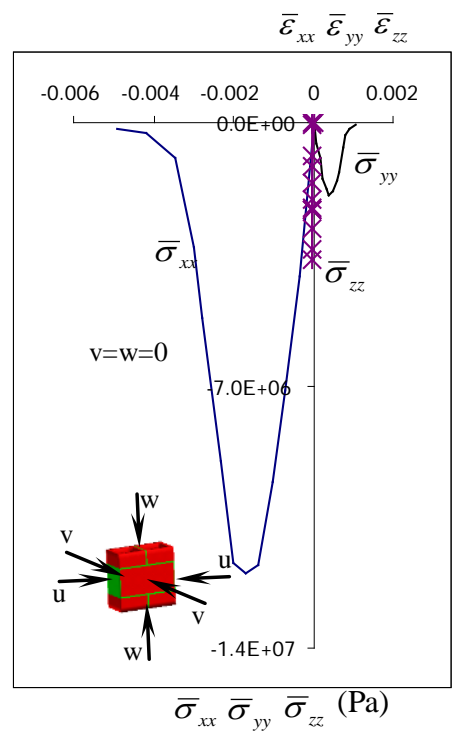

(e)

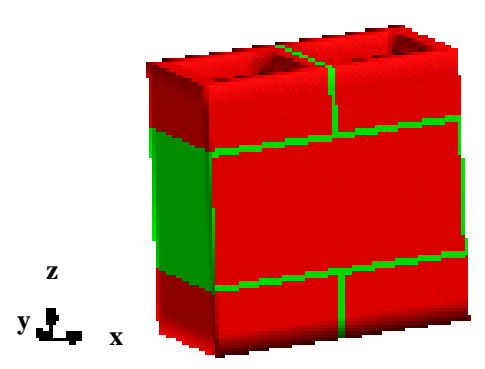

$\mathrm{u}: \mathrm{v}: \mathrm{w}=2: 1: 2$

$\bar{\sigma}_{x x} \bar{\sigma}_{y y} \bar{\sigma}_{z z}(\mathrm{~Pa})$

(f)

$\bar{\varepsilon}_{x x} \bar{\varepsilon}_{y y} \bar{\varepsilon}_{z z}$

$\bar{\sigma}_{z z}^{\bar{\sigma}_{x x}} \bar{\sigma}_{y y}$

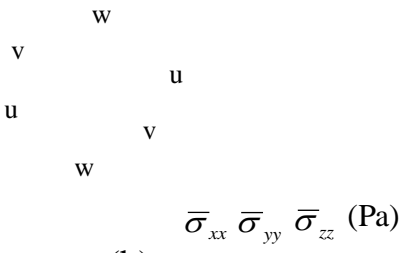

(h)

Fig. 5 Stress-strain relations of the basic cell in compression-compression stress state 


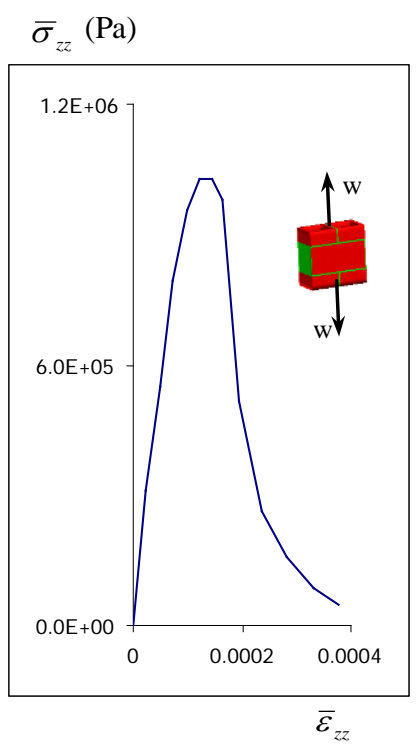

(a)

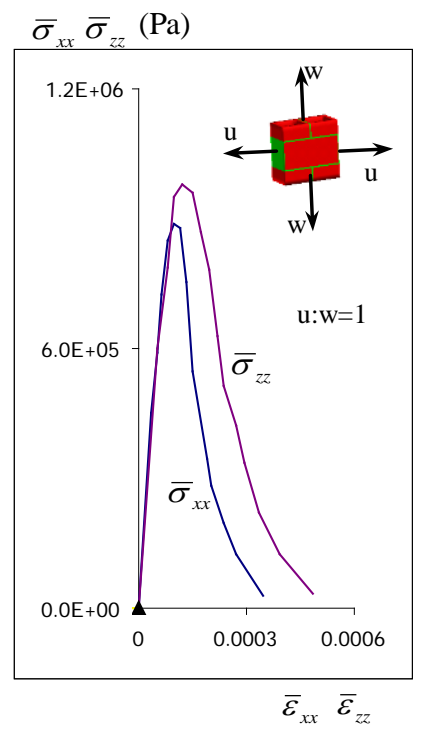

(d)

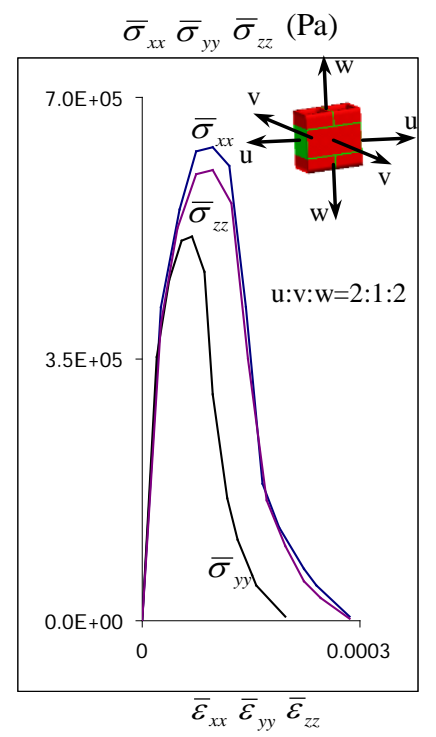

(g)

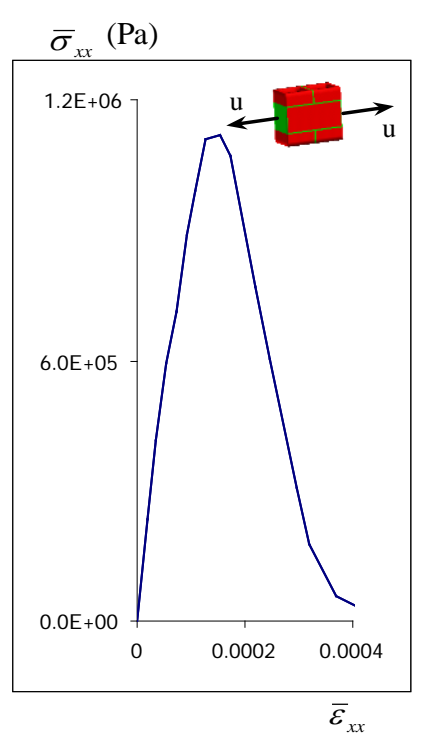

(b)

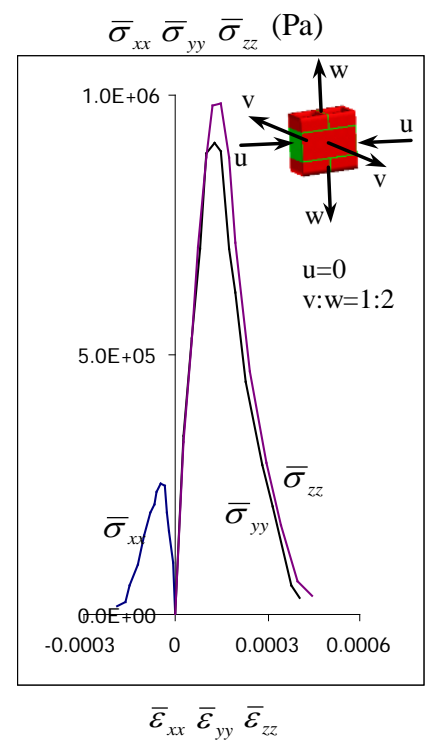

(e) $\bar{\sigma}_{y y}(\mathrm{~Pa})$

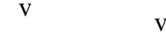

(c)

$\bar{\sigma}_{z z}(\mathrm{~Pa})$

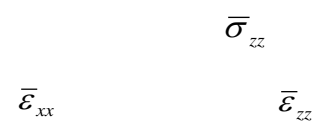

$\mathrm{u}: \mathrm{w}=1: 1$

$\bar{\sigma}_{x x}$

W

u W $\bar{\sigma}_{x x}(\mathrm{~Pa})$ (f) 


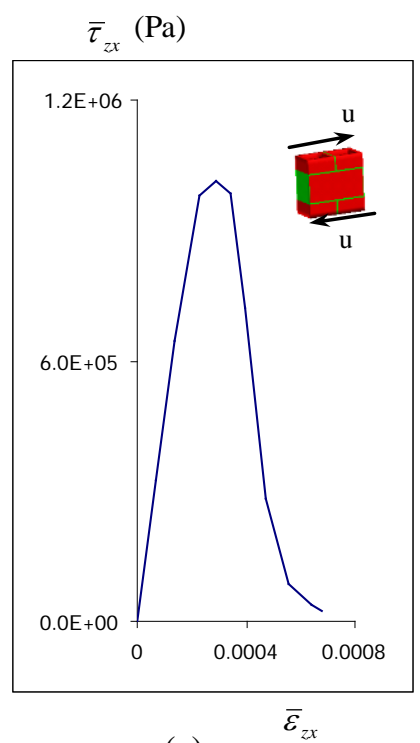

(a)

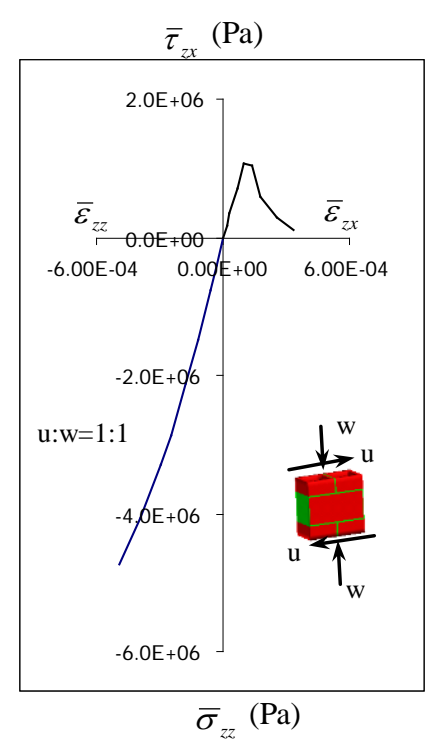

(d)

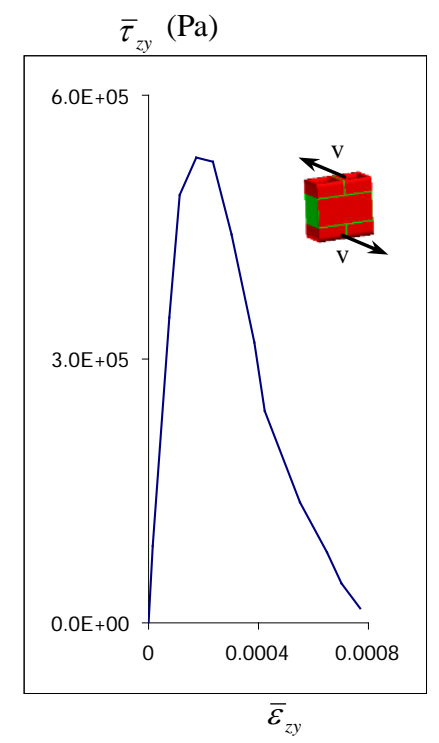

(b)

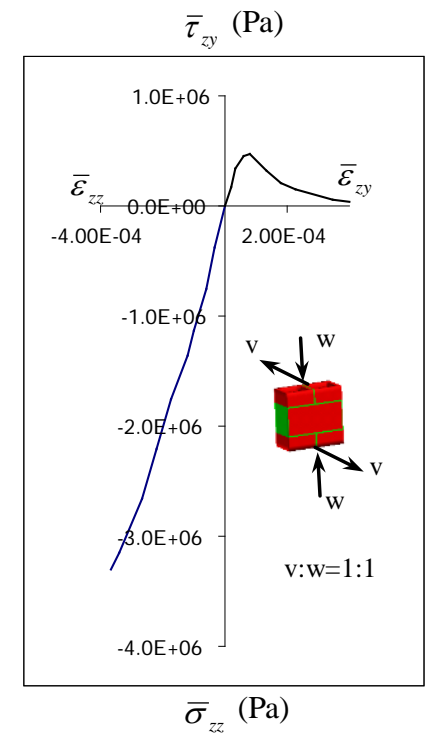

(e) $\bar{\tau}_{y x}(\mathrm{~Pa})$

u

u

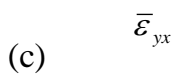

$\bar{\sigma}_{z z} \bar{\tau}_{z x}(\mathrm{~Pa})$

$\bar{\sigma}_{z z} \quad{ }^{\mathrm{w}}$

u

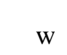

$\mathrm{u}: \mathrm{w}=2: 1$

$\bar{\tau}_{z x}$

(f)

Fig. 7 Stress-strain relations of the basic cell in compressivetension-shear stress state 


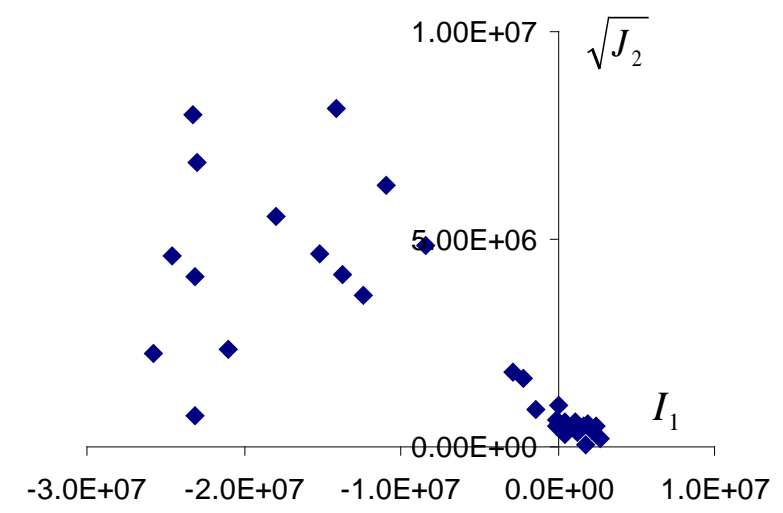

a. Simulated two-invariant points in $I_{1} \sim \sqrt{J_{2}}$ space

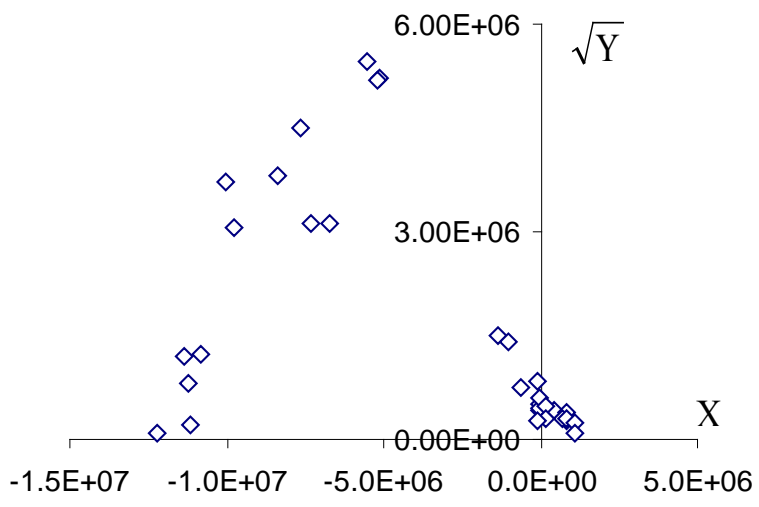

b. Simulated equivalent strength envelope in $\mathrm{X} \sim \sqrt{\mathrm{Y}}$ space

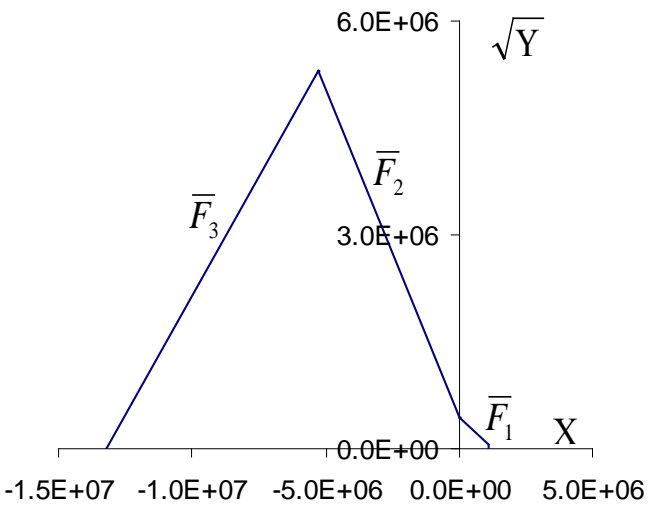

c. Yield surface of masonry in $\mathrm{X} \sim \sqrt{\mathrm{Y}}$ space

Fig. 8 Strength envelope for masonry in $\mathrm{X} \sim \sqrt{\mathrm{Y}}$ space 


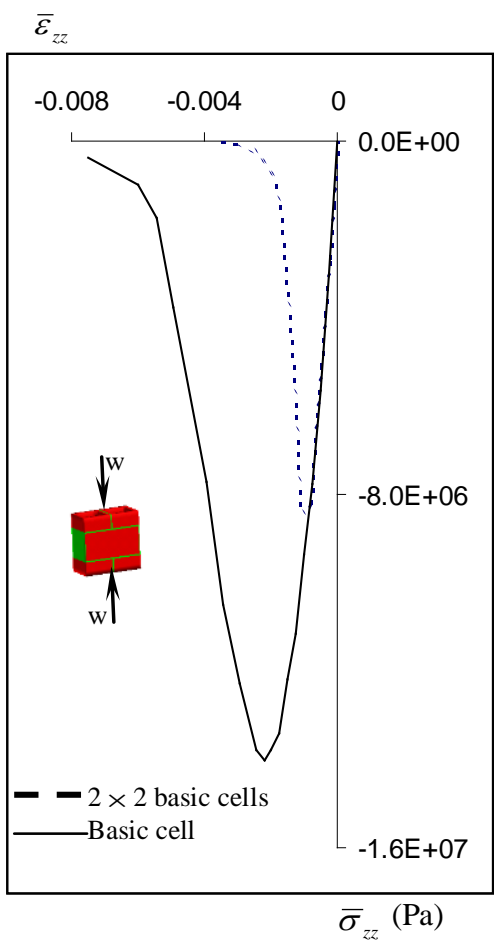

a. Uniaxial compression $\bar{\sigma}_{z z}(\mathrm{~Pa})$

$2 \times 2$ basic cells

Basic cell

W

$\bar{\varepsilon}_{z z}$

b. Uniaxial tension

Fig. 9 Comparison of the simulated stress-strain relations of two different sizes of the masonry unit 


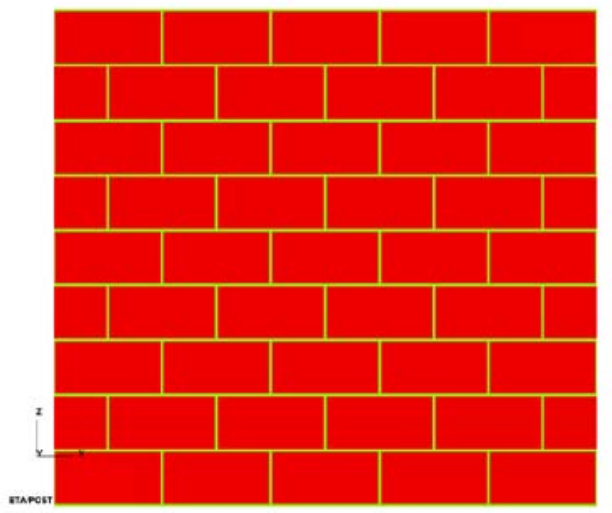

a. Distinctive model of masonry panel

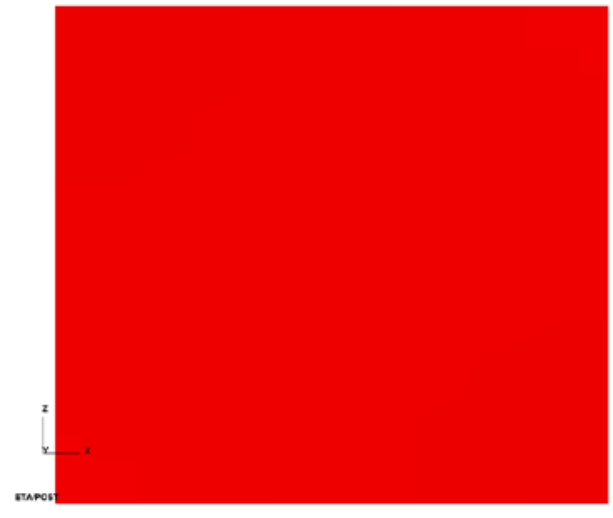

b. Simple homogenized model of masonry panel

Fig. 10 Distinctive model and simple homogenized model of the hollow concrete masonry panels

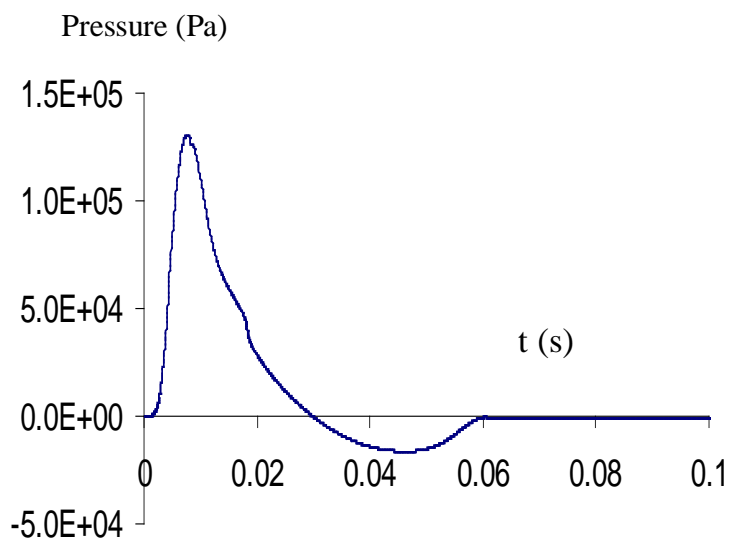

a. $40 \mathrm{~m}$
Pressure $(\mathrm{Pa})$

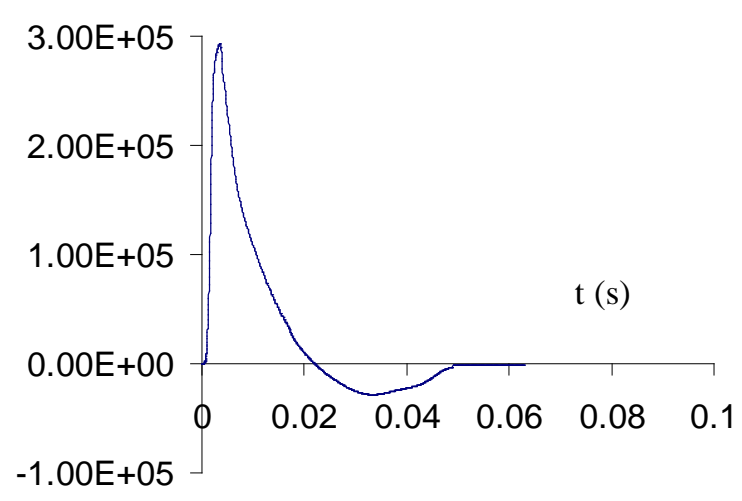

b. $30 \mathrm{~m}$

Fig. 11 Pressure time histories of airblast loads at 40 and $30 \mathrm{~m}$ from charge centre 


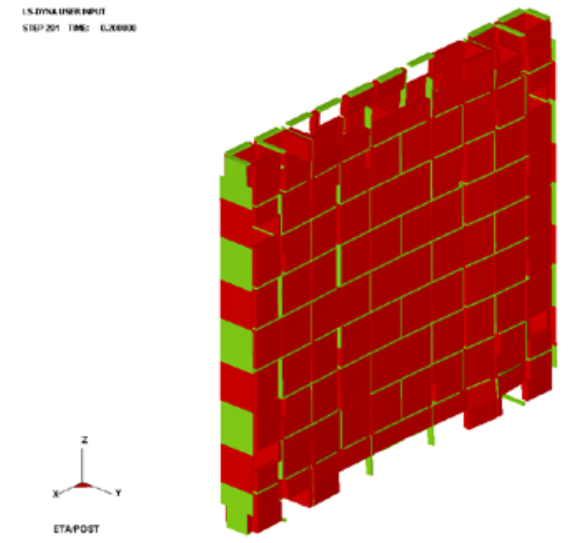

a. Distinctive model of masonry panel

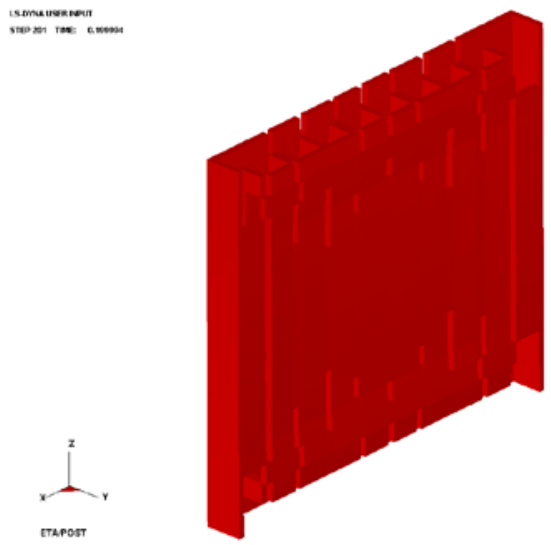

b. Simple homogenized model of masonry panel

Fig. 12 Deformation of the masonry panels to airblast loads at 40 from charge centre at $0.02 \mathrm{~s}$ with distinctive model and simple homogenized model

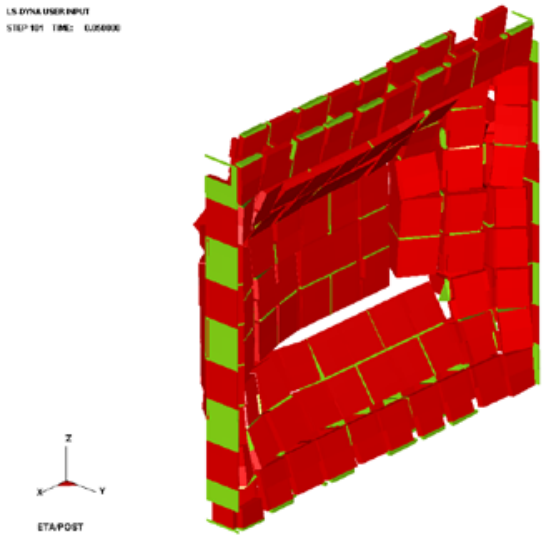

a. Distinctive model of masonry panel

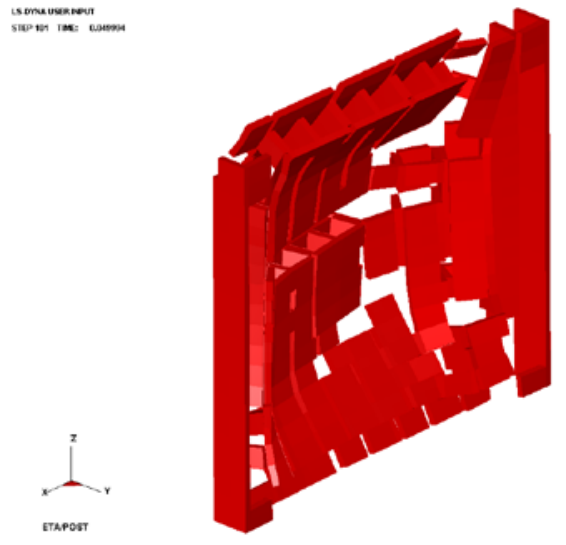

b. Simple homogenized model of masonry panel

Fig. 13 Deformation of the masonry panels to airblast load at $30 \mathrm{~m}$ from charge centre at $0.05 \mathrm{~s}$ with distinctive model and simple homogenized model 